\title{
Challenges of the Elderly In Zambia. A Systematic Review Study
}

\author{
Masauso Chirwa \\ Roy Kalinda \\ University of Zambia
}

doi: 10.19044/esj.2016.v12n2p351 URL:http://dx.doi.org/10.19044/esj.2016.v12n2p351

\begin{abstract}
Aging is a phenomenon that is found worldwide. In developed countries, the elderly living conditions are better relative to their counterparts in developing countries. Zambia has a population of slightly over 500,000. A big number of these people reside in rural areas. The aim of this paper was to investigate the challenges experienced by the elderly in Zambia. This was a desk study that used both a quantitative and qualitative methods focusing on the analysis of available literature on aging in Zambia. The results revealed that households with old people are among the poorest in the country. The other challenge faced by the elderly especially in rural areas is social stigma arising from being suspected of practicing witchcraft. They are also left out of the HIV/AIDS statistics and programmes: Currently there seems to be no available HIV/AIDS statistics and programmes for the elderly people aged 65 years and above. Lack of family support and the burden of orphans. Most of the elderly are poor and cannot manage to support their grand children in terms of school, decent shelter, clothing and medical care.
\end{abstract}

Keywords: Challenges, Elderly, Poverty, Zambia

\section{Background}

The process of population aging is a phenomenon that has characterized most countries particularly the advanced countries. In countries such as China, United States of America (USA) and Europe, the populations are aging or the old people are more than the younger ones (Moser and Holland, 1992). However, it is reported that the process of aging is less dramatic in USA than in China and Europe due to both the higher fertility and a large number of young migrants (Population Aging in China, Europe and USA, January 2008). In Zambia, according to Central Statistical Office (CSO), there were about 500, 000 people aged 65 years and above living in the year 2007 and that the elderly people (aged 65 and above) in the country 
were a minority compared to other population groups (CSO 2007). According to the Census data for 2010, the elderly people aged 65 years and above were the lowest percentage of the population at 2.6\% (Census 2010).

However, some scholars submit that this $(500,000)$ might be a conservative figure and that there might be more people living in rural areas who might be difficult to capture. Data from census 2010 shows that there is a higher concentration of people aged 60 years and above in rural areas (Census 2010). This implies that a big number of elderly people in Zambia reside in rural areas. In the year 2000, the elderly population living in rural areas was $3.5 \%$ of the total country population while the elderly living in rural areas were 1.3\% (Census 2000). The 2010 Census of population and housing put the total population of elderly people living in rural areas at $3.2 \%$ while that of the elderly in urban areas were at $1.8 \%$ of the total country population (Census 2010). Some observations indicate the growing number of senior citizens in Zambia is proving to be challenging to the government especially with regard to service provision for the aged (Cliggett, 2001; Colson and Scudder, 1988). Improvements in medical services in both urban and rural areas is credited for keeping Zambians live longer but health officials are worried about who will look after the swelling ranks of the aged (Mapoma and Masaiti, 2012; Schubert, 2005).

The Zambian population constitutes the youth as a majority in the country. According to the Living Conditions Monitoring survey for 2004, about 67 percent of the population were aged between 0 to 24 years of which 44 percent were aged between 0 and 14 years and 23 percent were youths aged between 15 and 24 years and that there was no significant difference in the distribution of the population by age group and between male and female (LCMS 2004). This shows that the majority of Zambians are the youth. And the same survey shows that the population aged above 65 years old only constituted 2 percent of the country's population. Of this percentage, the males were 3 percent while the females were 2 percent. Thus the elderly population as at 2004 was a minority group and this group had males slightly more than the females. The 2010 census indicated that the population below 18 years had the highest percentage at 52.5\%. The population aged 15 to 24 and 15 to 35 had proportions of 20.8 and 36.7 percent respectively (Census 2010).

Data from the census 1990 shows that the elderly in Zambia in 1980 were 4.1 percent (males 4.4 percent, females 3.8 percent), while in 1990, this population declined to 2.5 percent (males 2.9 percent, females 2.2 percent) (CSO, 1996; Kamwengo, 2001). The 1990s show a steep decline in the numbers of the aged or elderly population in the country. The percentage decline from 1980 to 1990 for both sexes was 1.6 percent and the male population continued to maintain a slight majority (Kamwengo, 2004). 


\section{Gender dimensions of the population}

Table 1 below shows the gender breakdown of the population as at 2010.

Gender breakdown of the population aged 65 years and above as at 2010

\begin{tabular}{|c|c|c|}
\hline Age group & Male \% & Female\% \\
\hline 65-69 years & 0.9 & 1 \\
\hline $70-74$ & 0.7 & 0.7 \\
\hline $75-79$ & 0.5 & 0.5 \\
\hline $80-84$ & 0.3 & 0.3 \\
\hline $85+$ & 0.2 & 0.3 \\
\hline
\end{tabular}

Source: 2010 Census of population and housing.

Table 1 above shows that there were slightly more females in the age groups 65-69 and those aged 85 years and above among the elderly population as at the year 2010. In terms of the gender gap among the aged, the difference is minimal at national level. However, it is important top note that the population sizes for both gender categories are very small compared to other age groups in the country. The data above suggests that there are very few people who live very long lives in the Zambian society whether male or female.

\section{The elderly in both urban and rural areas in Zambia.}

This section looks at the percentage of elderly people from an intragender perspective in both urban and rural areas.

Table 2. Elderly in females in urban and rural areas as at 2010

\begin{tabular}{|c|c|c|}
\hline \multirow{2}{*}{ Age group } & Rural & Urban \\
\cline { 2 - 3 } & & Female\% \\
\hline $65-69$ & 1.2 & 0.7 \\
\hline $70-74$ & 0.9 & 0.5 \\
\hline $75-79$ & 0.6 & 0.3 \\
\hline $79-80$ & 0.3 & 0.2 \\
\hline $85+$ & 0.3 & 0.2 \\
\hline
\end{tabular}

Source: Census 2010.

Table 2 above shows that in 2010, there were more elderly females in rural areas than those in urban areas in all age groups indicated above. The intra-gender gap was wider between age groups 65-79 years old. There was intra-gender equality in terms of of age from 80 years and above in both urban and rurl areas. From the above table it can be stated that there were more elderly females in rural trhan urban areas from the age of 65 year to 79 years. The factors behind this scenario are worth investigating. 
Table3. Intra gender comparisons of elderly males in both urban and rural areas in 2010

\begin{tabular}{|c|c|c|}
\hline \multirow{2}{*}{ Age group } & Rural & Urban \\
\cline { 2 - 3 } & Males & Females \\
\hline $65-69$ & 1 & 0.7 \\
\hline $70-74$ & 0.8 & 0.5 \\
\hline $75-79$ & 0.6 & 0.3 \\
\hline $80-84$ & 0.3 & 0.1 \\
\hline $85+$ & 0.3 & 0.1 \\
\hline
\end{tabular}

Source: Census 2010

Table 3 above shows that there were more males in rural areas for all age groups as at 2010. One would expect that the urban areas would have greater capacity to sustain lives of elderly people due to the abundance of urban quality health care services and better nutrition, but on the contrary, rural areas seem to have greater capacity to sustain life of the elderly than the urban areas. The table shows that the urban to rural gaps in terms of numbers are wide at all levels.

What is important to note is the fact that the population aged 65 years and above has continued to decline from 4.1 percent in 1980 to 2.5 percent in 1990 and slightly increased to 3 percent in 1996 and declined to $2.9 \%$ in 2003 and further declined to 2percent in 2004 and in 2010 there was a slight increase to $2.6 \%$ (Census 2010, UNDP 2003). This trend shows that this population category is on a continuous decline and is a source of concern not only to researchers but also to policy makers too to find solutions to the problems of the aged in Zambia.

\section{Distribution of the elderly by province}

At provincial level, Lusaka province had the lowest of the elderly people aged 65 years and above at $1.6 \%$ while Western [province had the highest percentage of the same elderly people aged 65 years and above at $3.9 \%$. In North Western province the elderly population was $2.9 \%$, in Northern Province they were 2.9\%, in Muchinga they were 3.0\%, in Luapula province the figure stood at $2.7 \%$, in Eastern province the population was $3.3 \%$, in Southern province the population was $2.5 \%$. Other provinces such as Central province the population stood at $2.8 \%$, while Copperbelt province recorded a population of $2.3 \%$ and lastly Lusaka had $1.6 \%$ of the elderly population aged 65 years and above. The number of elderly people in all provinces is very minimal compared to other population groups in the country. Statistically, the elderly people of the age 65 are a minority and the trend continues as the years advances. This is a sign that the population does not have a long life span others there would have been a fair representation of the elderly people in the country in all communities. 
Aim

The overarching aim of this paper was to investigate the challenges experienced by the elderly in Zambia.

\section{Research Questions}

This study sought to answer the following questions:

- What are the major challenges faced by the aged in Zambia?

- To what extent have the aged been involved in HIV/AIDS programmes?

- What are the gender relations among the elderly in Zambia?

\section{Methodology}

This was a desk study that used both a quantitative and qualitative methods focusing on the analysis of available literature on aging in Zambia. Various sources were consulted, and these included; Human Development Report of 2005 and 1992, official websites for UNDP and World Bank. Peer reviewed articles were also collected from University of Zambia library databases. Journals were collected from databases such Academic Search Elite (EBSCO), Science Direct, DOAJ, and JSTOR. Others were LibHub, PAIS (Public Affair Information Service), Social Science Citation Index, and Google Scholar. Data was also collected from UNDP, IMF, World Bank and UNESCO's official websites. Data was also collected from books. The major key searching words for the articles from the databases were aging, gerontology, and social development. We did searches using a combination of the above words. We also thoroughly went through all the articles to ensure that they were of appropriate quality, and we further searched all the journals' websites to ensure that the articles were from peer- reviewed journals.

\section{Inclusion criteria and Instrumentation}

Both primary studies and reviews relating to aging in Zambia were included. The studies were assessed for inclusion and categorisation by the two researchers RK and MC. The studies were categorised according to broad themes: aging, livelihood, social support and population trend, among others.

\section{Analysis}

The initial stage of analysis began with reading and re-reading the articles to familiarise ourselves with the data with the aim of drawing themes rather than letting themes simply emerge. We then began to extract information from the data towards generating ideas that could be assessed in a meaningful way. This process involved asking questions about the data we 
were reading thereby formulating themes and meaning rather than paraphrasing (Bryman, 2012; Creswell, 2007).

\section{Results and Discussion}

Problems faced by the elderly people: The observed decline in the numbers of the elderly people in the country suggests that there is a problem that has been going on but not fully either addressed or known by the policy makers or it is an indication that the elderly are not a visible category in the decision making bodies in the country. Some probable problems affecting this group or category of people are discussed below:

Poverty: Data revealed that households with old people are among the poorest in the country. For instance the Living Conditions Monitoring Survey (LCMS) for 2004 revealed that 78 percent of households headed by individuals aged 60 years or older fell below the poverty line as was the case for households headed by children aged 11 and 19 years old (LCMS 2004). Poverty has its own offshoots such as diseases that could be the leading to the deaths of the people aged 65 years and above. In Lusaka, Moser and Holland found out that the poorest are the very young, sick, disabled and the elderly (Moser and Holland 1992). Capacity to afford quality health care becomes a problem among the poorest that include the elderly.

On the deaths it was found out that the rural areas experienced more deaths in the age groups 65 years and above that the urban areas (LCMS 1996). With the increase in poverty particularly in the 1990s, it is highly likely that the deaths were resulting from the failure of the rural aged to access medical services due to high poverty levels in the rural areas. What compounds the elderly particularly the poor is that they are out of pension and the government has no scheme to support the old people in the country. The absence of a scheme for the aged people makes them vulnerable to poverty and diseases after retirement.

Moreover, there is no policy that supports the poor whether they have worked before or not. And the government pension is specifically for the people who earlier on worked for the formal sector. On this issue, the IRIN/Plus News last year 2007 commented that despite being a signatory to the International Conventions on the elderly including the Madrid 2002 Plan of Action on the ageing which calls on governments to recognize the rights of the aged/older people, Zambia has no legislated policies for the aged. Consequently the aged are left out of the development programmes and policies. Even though in terms of medical care, government has introduced a free medical scheme for the people aged 65 and above, this only covers consultations and other medical requirements such as x-rays, treatments, drugs among others have to be borne by the old people themselves. Consequently access to proper medical care, which is important for the well 
being of the aged, is not fully accessed in Zambia particularly among those who are poor and have no support from the immediate relatives.

Isolation from the communities due to stigma: One of the commonest problems faced by elderly people especially in rural areas is social stigma arising from being suspected of practicing witchcraft. Not only have they faced this stigma, but also some have been killed because they are the suspects for unexplained deaths in rural communities. For instance, the Karavinas in Northwestern and Western provinces have been killing a lot of old people who they suspect top practice witchcraft. This problem has been experienced by a lot of old people in rural communities. According to IRIN/plus news for 2007, Zambia's elderly people are faced with double jeopardy: they are shunned by communities as witchcraft practitioners and they have little understanding the pandemic HIV/AIDS. Interestingly, social workers and police have already sounded the alarm over increasing violence against the elderly. Older women and men are often branded as wizards and witches blamed for the deaths of young people, poverty and other misfortunes (. Even though such violations are going on in society against the aged, there seems to be no programmes that are aimed at educating the rural communities on the importance of respecting the rights of the elderly in the communities.

Left out of the HIV/AIDS statistics and programmes: Currently there seems to be no available HIV/AIDS statistics and programmes for the elderly people aged 65 years and above. The available statistics and programmes target the populations aged between 15 and 49 years of age. This implies that at the policy making level in the health sector, the elderly people are assumed not to be sexually active. In Zambia today there are many programmes that deal with the youth and workers who are assumed to be sexually active but there are no programmes to deal with the elderly people. The aged are only statistics when it comes to their role in taking care of the AIDS orphans. The VCT programmes are oriented and administered by the youths most of the times if not all the time. In 2012 the Zambian government's report on HIV and AIDS indicated that HIV prevalence among adults aged 15-49 reached its peak in the 1990s at 23\% in 1992, rising from $20 \%$ in 1990 . It reduced to $15.6 \%$ in 2002 before rising to $16 \%$ in 2005 and it fell to 14.3\% in 2008 (GRZ National Report 2012). This is a classic example of how information about the elderly people is not gathered as though this category of the community is not infected with the HIV. The aged people though they are a small minority in the entire population are equally affected by the HIV pandemic and some have died of AIDS. Statistically on HIV, they are invisible.

On the contrary, the elderly especially the men are sexually active and some have continued to marry young women and even abuse or defile 
young girls in their quest to look for an AIDS cure (belief in the virgin cure). This practice is contrary to the view that the elderly people are not sexually active and hence left out of the HIV/AIDS statistics. IRIN/Plus news for 2007 repots that worldwide, over 2.8 million people over the age of 50 years are infected with HIV/AIDS but this group is largely ignored by HIV awareness campaigns and information. Older women are susceptible to HIV infection due to the thinner walls of the vagina after they have reached their menopause, while older men take younger women and are at a higher risk of getting the virus. Yet most of the HIV prevention campaigns target younger people. This finding calls for policy interventions to save the older generation from the pandemic.

The Elderly not given priority on Voluntary Counseling and Testing (VCT): The VCT programmes are very common and usually target the young population who are in schools, colleges, and universities and other popular places. The VCT services are rarely available to the aged or elderly population who are perceived to be sexually inactive both in rural and urban areas. IRIN news reported that the Senior Citizens Organisation is calling on government to introduce more elderly friendly VCT services which are generally youth friendly and are administered by the young people in the majority of cases (IRIN news 2007). There are no open discriminatory practices against the elderly population when it comes to provision of services, which are usually found in clinics, health centres, and hospitals. The argument is that these services are not culturally sensitive to people of different age groups. While the youth find it easy to seek VCT services from fellow youth running VCT programmes, elderly people do not find it easy to divulge information about their private lives to young people. There are generally very few elderly people involved in the running of VCT services in different communities. The administration of VCT services is predominantly in the hands of the youth and this makes it difficult for the elderly people to access VCT services. If the elderly were a priority in the provision of VCT services, efforts would have been made to involve a good number of elderly people in the provision of these services to their peers.

Furthermore, the Global Age Watch for 2015 ranks Zambia as number 90 out of 96 countries where the welfare of the aged were assessed. The report states that Zambia ranks low in the Index, at 90 overall. It ranks highest in the capability domain (67). This fall from last year's ranking (57) is due to a change of indicator from labour force participation rate to employment rate. The country also ranks low in the enabling environment domain (84) due to older people's low satisfaction with safety (34\%). It ranks at 89 in the income security domain, with low pension coverage (7.7\%), the highest old age poverty rate in the region $(22.9 \%)$ and the lowest rate of relative welfare $(78 \%)$ among older people in its region. Zambia ranks 
lowest in the health domain (91), with values below the regional averages on all indicators (Global Age Watch 2015).

Isolation from information: Older people know very little about HIV/AIDS and other diseases particularly if they are illiterate. This is due to the fact that programmes on health are rarely targeted on this population too. As argued above, any focus on the elderly populations is usually confined to their responsibilities as care givers for the infected AIDS orphans. The needs of the aged and their susceptibility to the pandemic are either disregarded in HIV programming or not given priority regardless of the fact that the elderly make 75 of the world's HIV infections (IRIN/Plus news 2007).

Given the above situation, there is need to have more information about the elderly in Zambia on several issues which among many include their knowledge of HIV and AIDS, their economic status and its implications on their health, their life styles and how this affects their well being, among others.

Lack of family support and the burden of orphans: For many years even today, the elderly people have been relying on their children as a form of social security in future and society equally teaches children to look after their parents in old age. As urbanization and other economic and social changes are taking place in society, the family ties are weakening leaving some sections of the family particularly the aged without support. The impact of HIV/AIDS has reversed this trend as more old people are in charge of supporting the young children especially the AIDS orphans in society. Seniors World Chronicle reports that more Zambians are breaking with tradition and putting their elderly parents in nursing homes. Others have succumbed to the HIV and AIDS pandemic leaving young children to the care of their grand parents.

Most of the elderly are poor and cannot manage to support their grand children in terms of school, decent shelter, clothing and medical care. Lack of social support and the burden of looking after orphans are the current realities of old age in Zambia particularly among the poor elderly people. The Zambia Human development report pointed out that the elderly are themselves over burdened by the incidence of orphaned children due to HIV /AIDS, reducing their own source of livelihoods (UNDP, 2003). On the same scenario, the United Nations Development Programme in 2007 observed the devastating effects of HIV and AIDS on the family social support systems and reported that even as family units are being destroyed, the social security system continues to be extremely weak. Community social structures and support systems, which existed to support households during illnesses and bereavements, are breaking down as they fail to cope with the numbers of sick people and deaths. In grandparent-headed households, many children drop out of school. The nutrition of children is 
affected; children have poor access to health services and are usually very poor. Grand parents may be too old to walk long distances to health institutions, work or produce for the family (UNDP 2007)

$H I V$ risk practices among the elderly: There are some serious risk practices among the elderly that make them vulnerable to HIV infections in communities but have not been given attention by the policy makers and anti-AIDS activists. There are traditional birth attendants in rural areas that do not have any information on how HIV is transmitted and on how to prevent contracting the virus. Yet these women who are usually elderly are exposed to blood during their work that may be infected with the virus. Secondly elderly people in communities usually prefer to seek or consult traditional healers for the ailments, which they usually have and if they have HIV infection this means that they delay their treatment so much that by the time they are diagnosed, the bodies are weak, and cannot take strong ARVs nor fight opportunistic infections.

Polygamy and gender relations among the elderly: The gender relations in our society are socially constructed in away that put the women in subordinate positions in both domestic and public sphere. In marriages, women are treated as minors while men have superior positions. Consequently, it is common to find even elderly men marrying several wives and still maintain sexual relations with sex workers or other sexually active young women who trade sex for money and gifts. Polygamy and infidelity among men put old women at the risk of being infected by their elderly husbands. The Demographic and Health Survey for 2013-14 revealed that polygyny is more common in rural than urban areas with $17 \%$ of the women and $10 \%$ of the men reporting to be in polygamous relationships/unions. Among the provinces, polygyny was highest in Southern province (26\%) of women and $16 \%$ of men being in polygamous relationships (ZDHS 2014).

Although polygamous marriages are common in rural areas, the major perpetrators are men and rich elderly men desire to marry young women who are presumed still more sexually active than the old men. Infidelity is polygamous marriages is high and is the channel for the transmission of HIV among the elderly in polygamous marriages. Information dissemination on HIV usually leaves out the elderly who are perceived to be sexually inactive but the practice of polygyny tells one that the elderly are still sexually active. This perception results in most of the programmes ion HIV to target the young people aged between 15-49 years who are perceived to be sexually active. IRIN news in 2007 revealed that contrary to this perception (that the elderly are not sexually active) reported that some elderly people are sexually active (IRIN news 2007).

Not much research has been done about the sexual behavior of the men and women who are aged 65 years and above. It is the manifestation of 
practices such as polygyny and the defilement cases where men above 65 years and above have been involved which are indicators that the mostly the elderly men are still sexually active even though they are left out of the HIV information programmes. These practices need in-depth study to fully understand their implications on the health of the elderly population particularly in the era of HIV and AIDS.

Widowhood and widower hood:

Lack of financial and material resources: The poverty levels in the country are highest among the poor widows, widowers, the aged and children. The major reason for this situation is lack of material and financial support to meet the basic needs of the communities. Most of the aged men and women rely on the well to do children, grand children and other family members for support (Mapoma, 2013). In situations where the relations are lacking or the majority are poor, there is a no or little support to the aged members of the community. The common resort for the aged poor [particularly those in urban areas are to seek support form social organizations that are dealing with the issues of the aged in the country. In the old people's homes, the life of the aged is difficult due to lack of resources to support them (Kamwengo, 2004).

With the current economic challenges the country is going through, the situation in many of the old people's homes is in dire stress as the means to meet their needs are inadequate compared to the numbers to be assisted materially and financially. It has been observed that older persons in Zambia experience many challenges ranging from lack of income, neglect, sickness, to abuse (Mapoma 2013; Mapoma and Masaiti, 2012). Older people in Zambia are also exposed to high levels of stress due to a number of factors. For instance, Zambia's sharp economic decline has seriously eroded the country's traditional support system for the elderly (Noyoo 2008).

The continuing economic decline in the country has exacerbated the lives of the aged people some of whom have completely no sources of income for food, health care, and decent accommodation among others. Poverty levels are high among the aged despite the fact that some of them worked before but there resources have been depleted over years because of lack of a social security system that would have investing their earned resources during working years (for those whore are retirees). Sickness is very common among a lot of the aged with serious complication that may require expert health care but resources to access quality health care are not available).

Loneliness: Loneliness among the most of the elderly people whether women or men is a common phenomenon. This results from weak social ties with family members or lack of children to act as a social security and support mechanism in old age. There are some families who perceive the 
elderly as an extra burden and usually leave them on their own if they live with family members or assign some poor lowly educated family member to live with them in rural areas and infrequently visit them. This is the case where the elderly person does not have financial and material resources. On Loneliness, Mapoma (2013) reported that there are some cases where old people do not have anybody to look after them and the lonely elderly people are in most cases very poor and have very weak social ties with their relatives. UNDP stressed that the weak social security system in Zambia exacerbates the situation of the elderly (UNDP 2003). This scenario compounds the situation of loneliness among the elderly people in different communities. As indicated earlier, the poor old men and women who have information about hospices resort to find their way to hospices or old people's homes to be cared for.

Dependence on others for care: One of the common phenomenon in society about aging is that the old people become dependent on other relatives to look after them. In some cases, as soon as they retire from employment, they begin to live with energetic relatives such as grandchildren or other members of the extended family who play a great role in domestic chores that were once done by the retirees. In cases where the elderly have no financial resources, they are completely dependent on other relatives for accommodation, food clothing, health care and many other necessities of life. On dependence of the elderly people on others, in 2003, UNDP observed that as soon as aging sets in around middle ages their health start getting affected by factors such as living conditions, reproductive history, work and home life demands, diet and exposure to infection and chemical agents. This weakens their capacity to work increasingly they become dependent on others (UNDP 2003).

As the elderly advance in age they become more and more dependent on relatives and children for support. In cases where they do not have relatives or children to lean on in old age, they usually go seek help from the old people's homes where they could be taken care. Absence of social support may lead to depression and other health related complications that shorten the life span of the old people who might have lived longer under the social support system. In 2007, UNDP further observed that in households that comprise the young and elderly, dependency on others increases because they are not able to contribute to any productive activity. Overall, HIV and AIDS pandemic have weakened the copying mechanisms of households and the available support networks may be unable to cope with the new situation (UNDP 2007). This scenario is common in many households where there are elderly people.

Poverty assessments in the early 1990s revealed that in urban Zambia the extended family households were more likely to live below the poverty 
line than nuclear units and that poor households had high dependency ratios (Moser and Holland 1992; Cliggett, 2011). There are cases where the aged people literally cannot trace their families due the long separation that urbanization brings between the urban and rural families and in cases of childlessness and the demise of children due to HIV pandemic. Such old people literally end up in hospices or established old people's homes where these facilities are accessible and available (Mapoma, 2013).

Research has pointed out that although the family or community was the ideal caring system for the aged, there were those who could not trace families due to urbanisation. There were attempts at the level of government to retain services for the old for old people who did not have families to look after them. It was for this reason that homes for the aged people continued to operate in Livingstone, Mufulira, and Ndola during the reign of Kenneth Kaunda and UNIP (Noyoo 2000). In a number of cases, the elderly if they do not have resources to continue living in urban areas, they may move or are moved to rural areas to live with relations in most cases under very difficult living conditions such as exposure to unsafe drinking water, poor quality food, inadequate health care, and poor accommodation and clothes among others.

\section{References:}

Canadian Census, 2006. http://www12.statcan.ca/censusrecensement/2006/dp-pd/hlt/97-550/Index.cfm?Page=INDX\&LANG=Eng Cliggett, L. (2001) Survival Strategies of the Elderly in Gwembe Valley, Zambia: Gender, Residence and Kin Networks. Journal of Cross-Cultural Gerontology 16: 309-332

Colson, E. and Scudder, T. (1988). For prayer and profit: the ritual, economic, and social importance of beer in Gwembe District, Zambia 19501982. Stanford: Stanford University Press.

CSO (1990) Census of Population and Housing. Lusaka, Government Publication.

CSO (1996) Gender Statistics Report. Lusaka: Government Publication. CSO (1996) Living Conditions Monitoring Survey. Lusaka, Government Publication.

CSO (2000) Census of Population and Housing. Lusaka, Government Publication.

CSO( Central Statistical Office) Living Conditions monitoring Survey, 2004, Lusaka, Government Publication.

CSO(2010)Census of Population and Housing, Lusaka, Government Publication 
Global Age Watch 2015. http://www.helpage.org/globalagewatch/reports/global-agewatch-index-2015-insight-report-summary-andmethodology/ Accessed on 13/11/15

GRZ(012) National Report-Zambia: The United Nations Conference on Sustainable Development-June 2012 (Rio + 20). Lusaka, Government Publication

IRIN/Plus News 2007. http://www.irinnews.org/report/74406/zambiagovernment-discards-the-elderly. Accessed 20/10/2015

Kamwengo, M. (2001), Ageing and the Elderly in Zambia: Perspectives and Issues. New Delhi, Sterling International.

Kamwengo, M. (2004), Growing Old in Zambia: Old and New Perspectives. New Delhi Sterling International.

Mapoma, C.C. (2013) Population Ageing in Zambia: Magnitude, Challenges and Determinants. [Ph.D. dissertation], University of Zambia, Department of Population Studies.

Mapoma, C.C. and Masaiti, G. (2012) "Social Isolation and Aging in Zambia: Examining the Possible Predictors,” Journal of Aging Research, vol. 2012, Article ID 537467, 6 pages, 2012

Moser .C. and Holland, J. (1992) Household Responses to Poverty and Vulnerability: Confronting Crisis In Chawama. Lusaka, Urban management Policy Paper Vol 4.

Noyoo, N. (2000) Social Welfare in Zambia. Lusaka, Multimedia Zambia.

Noyoo, N. (2008) Social Policy and Human Development in Zambia. Lusaka, University of Zambia Press.

Phiri, N. A. (2004) phenomenological study of ageing amongst the older persons in Zambia [Ph.D. dissertation], University of South Africa, Department of Health Studies.

Population Aging in China, Europe, USA, January 2008. https://www.census.gov/prod/2009pubs/p95-09-1.pdf.

Schubert, B. (2005) The Pilot Social Cash Transfer Scheme- Kalomo District, Zambia. CPRC Working Paper 52. Berlin, Chronic Poverty Research Centre.

UNDP: Zambia Human Development Report 2003. Lusaka, Government Publication

UNDP: Zambia Human Development Report 2007 www.salvationarmy.org/zambia/F71F9C2ACAF93B

United Nations Population Fund. (2008) World Population Status Report. New York, United Nations Publications. 